\title{
Anthropology Through Development: Putting Development Practice into Theory
}

Edited by Amy Pollard and Alice Street

\section{Editorial introduction}

This special issue of Anthropology Matters frames the canonical question for development anthropologists in reverse. Instead of asking how anthropological theory might be put into practice in development, it asks how engagements with development policy and practice might transform anthropology. What kinds of theoretical insights have emerged from the anthropology of development? What does the overlapping language of anthropology and development mean for ethnographic methodology? How do relationships between anthropologists and development professionals affect the research process? What can anthropologists learn from development work?

These are questions that have been important for both of us, as editors, as we traversed the boundaries of anthropology and development during our careers. Like many of authors in this collection, between us we have worked as academics, consultants, for NGOs and for government agencies - 'cross-pollinating' between the spheres of anthropology and development as we did so. We have found that working across these boundaries can be humbling for both sets of expertise, and suggest that the flow of insights between 'research' and 'practice' can be very much a two-way process.

The performance-based culture of contemporary academia creates unique challenges for today's early career anthropologists. The pressure to publish and the conservative parameters around what counts as a "REFable" publication can inhibit experimental engagements with different audiences and lead to a reduction of the anthropological endeavour to narrow careerism. Meanwhile, growing institutional debates about 'impact' in academia resuscitate the ideals that often drew people to anthropology in the beginning, and raise important questions about what anthropology might achieve beyond the walls of the university.

The contributors to this issue of Anthropology Matters have all found the friction-rich interactions of development practice to be productive spaces in which to grapple with these questions about the process, purpose and value of anthropology. As anthropology moves on from an exclusively critical view of development work, and seeks instead to attend to the complex agency of those involved in it (Mosse 2005), a host of new opportunities emerge for the discipline. These not only make for more nuanced accounts of development policy and practice, but may also present a rich set of gifts to anthropologists working throughout the academy. 


\section{Opportunities from Aidland}

The diverse papers in our collection exhibit three inter-connected themes, which describe how anthropology can advance itself through engagement with development:

\section{Reflexive interventions}

Working with those in Aidland (Eyben 2007) can be an invaluable tool for anthropologists to develop their reflexivity, and gain a better sense of how they themselves inhabit the social contexts that they study. Since the 1980's, anthropologists have been highly sensitive to the politics involved in writing about and representing others. The contributors to this special issue draw on their experience as development professionals working in challenging contexts of poverty, conflict and trauma to identify ways in which anthropologists might be similarly reflexive about their practice.

Campregher describes how development agents can act as a third party in "chains of translation" between local people and anthropologists - enabling anthropologists to triangulate their findings and gain a better perspective on themselves as an actor in the field. This entails not only gaining a new vantage-point on how anthropologists produce knowledge, but also how their attempts to produce knowledge are incorporated into other people's endeavours to improve their lives. He describes, for example, how his fieldwork strengthened the status of community leaders as spokespersons in relationships with development agents.

Kraemer takes these insights further to argue that anthropologists should actively seek to make positive interventions in the lives of their collaborators. She describes how an oral history project undertaken in Madagascar generated an appetite from the research participants to gain 'a reply' as they described how dispossession of land and natural resources were affecting their livelihoods. Published on the radio and in other popular media in Madagascar, their stories provided important leverage in their interactions with government. Kraemer stresses that co-authoring anthropological accounts with communities not only increases the political weight of these texts, but also their legitimacy. The papers by both Campregher and Magrath indicate ways in which anthropologists could draw on the tools for advocacy that development presents should they act as mediators between communities and powerful groups.

In contrast to Magrath's emphasis on positive engagement, Fèvre describes the dangers associated with interviewing informants about trauma, pain and grief. She suggests that anthropological training should draw from our 'sister disciplines' in psychology, counselling and sociology, to prepare researchers for the impact they may have. During her fieldwork in post-tsunami Aceh, Fèvre found that her status as both a development worker and anthropologist heightened the ethical issues and the accountability associated with gathering life stories from those affected by the disaster. The attendance of development workers to the traumatic and economicallydeprived contexts of their interventions provides an important impetus for anthropologists to reflect on the affective, as well as representational, powers of anthropological methodologies. 


\section{Advancing theory}

Anthropology has been historically proficient in highlighting the cultural omissions and assumptions that underpin the production of knowledge in the development industry. By contrast, several of the contributors to this special issue draw on their experiences in the practice of development to flag up systematic omissions in anthropological theorizing of power, politics and development.

Magrath proposes that development practice can highlight the "blind-spots" of anthropological knowledge production. She argues that anthropologists, steeped in a Euro-American, Foucauldian theories of governmentality have been blind to those spaces where the techniques of governmentality are desperately needed as the basis for extending basic services to a rural citizen majority, and where they are actively strived for by government, development actors and publics alike. Instead of criticising the discursive construction of "weak states", as anthropologists might once have done, Magrath compels us to take the objects of development knowledge as prompts for anthropological enquiry, and insists on their value in encouraging anthropologists to rethink their theorizations of power in such state-spaces.

Development poses new challenges for anthropologists and opens out spaces for analysis. Reflection on the limitations of our theoretical toolkit can also be an impetus to look to other disciplines altogether. While Magrath uses the objects of development to inform anthropological theory, Campregher suggests that the "blind spot" is the role of the anthropologist herself. He finds it useful to draw on the theoretical tools and language of science and technology studies in order to develop a "symmetrical" approach that analyses anthropologists, development workers and development recipients in the same way.

The metabolism of development is much faster than anthropology (and academia in general) If anthropological conversations span years - decades even - development brings issues to the table that are immediately pressing. The imperatives of finding theories that are immediately adequate and relevant to the real-life problems that affect people's lives in contexts of development may demand that anthropologists engage in an active "borrowing" from both the fields of development and its "sister disciplines" (Fèvre, this issue).

\section{Productive translations}

A common thread running through the papers included in this special issue is the sheer messiness, unpredictability and disjuncture that characterises both relationships between development workers and their recipients, and between anthropologists and their collaborators. This is important for analysing the situations that anthropologists work in and for considering the effects of our studying them.

In varying ways the contributors to this special issue each explore the productive effects of these misunderstandings and slippages. Fèvre describes how tsunami survivor's memories of trauma become reconfigured in relation to the transformations and socio-economic improvements brought about by post-tsunami reconstructive efforts and the potentially therapeutic intervention of her own oral history project. 
Campregher describes the "chains of translations" by which the different agendas of development workers, recipients and anthropologists are appropriated and re-animated by one another. Magrath highlights the disjuncture and limitations of state-power as productive moments for anthropology itself.

These messy translations are addressed head on in Kraemer's account of 'productive misunderstandings' between NGO staff and villagers. Drawing on Anna Tsing's theorisation of "friction" (Tsing 2004), Kraemer describes how "creative translations" between differing rationalities ultimately allowed for new forms of social action, modes of knowledge production and social representation, which challenged powerful groups of actors. Kramer's analysis is important in suggesting that the inherent difficulty of 'accuracy' in ethnographic description may in fact be something useful and valuable to anthropological work. There are similarities here with Fèvre's suggestion that, in places where the interview process may partake in people's attempts to come to term with personal traumatic experiences, to allow silences, omissions and spaces of not-knowing within the dialogue can be important for the healing process and anthropological project alike. Perhaps, we suggest, the limitations of anthropology knowing are what enable ethnography to make its interventions productive.

\section{Conclusion}

Gaining the full benefits of anthropology through development requires a change in attitude. Whether it does so deliberately or not, anthropology changes the world. Even when fieldwork is conducted in its most conservative forms, the act of living with people and collecting data cannot help but impact on the lives of those we study. The writing-up and publication process affects them too - as well as impacting on wider spheres. Anthropology can benefit from the experience of development, as a field in the business of 'changing the world', to ensure that it does so as mindfully as possible. The papers collected here build on a long history of incorporating anthropological methodologies into development practice by inversely exploring how the experiences, considerations and motivations of development workers can generate new reflections on relationships between anthropological theory and practice. Such engagements may be a source of significant strength for early-career anthropologists, whether they seek to bolster our discipline through this period of academic crisis, or find new arenas for their skills. Our experience is that these two agendas may be one and the same.

\section{References}

Eyben, R. 2007. 'Labelling People for Aid' in Rosalind Eyben and Joy Moncrieffe (eds.) The Power of Labelling: How People are Categorized and Why it Matters, London: Earthscan.

Mosse, D. 2005. Cultivating Development: An ethnography of aid policy and practice. London: Pluto Press.

Tsing, Anna. 2005. Friction: An Ethnography of Global Connection. Princeton and Oxford: Princeton University Press. 


\section{About the editors}

Dr Amy Pollard is currently Lead Analyst on aid effectiveness at the Catholic Agency for Development (CAFOD). She completed her PhD in Social Anthropology at the University of Cambridge in 2009. Her thesis was an ethnographic study of aid donors in Indonesia, which examined the politics of their institutional struggles. She has previously worked for the UK Department for International Development (DFID), and the Overseas Development Institute (ODI). Her theoretical interests revolve around knowledge, power, institutions and doubt.

Contact: pollard.amy@gmail.com

Dr Alice Street is a Nuffield New Career Development Fellow in the Department of Anthropology at the University of Sussex, UK and a Visiting Fellow in the School of Culture, History and Language at Australia National University. Her doctoral research, based on ethnographic fieldwork in a Papua New Guinean hospital, explored the politics of personhood and biomedicine in spaces of resource-shortage and stateweakness. Her current research focuses on practices of state-building in the Papua New Guinean health system and entails a research partnership with donor agencies, the PNG government and academics in Papua New Guinea.

Contact: a.street@sussex.ac.uk 